\title{
Environmental Scanning Electron Microscopy as a Useful Tool for Taxonomical Documentation of Parasitical Helminths.
}

\author{
Eva Tihlaříková ${ }^{1}$, Vilém Neděla ${ }^{1}$ and Šárka Mašová \\ 1. Environmental Electron Microscopy Group, Institute of Scientific Instruments of the CAS, Brno, \\ Czech Republic. \\ 2. Department of Botany and Zoology, Faculty of Science, Masaryk University, Brno, Czech Republic.
}

Helminthiases are parasitic infections which may cause important diseases. Their research by veterinary and medical scientists is very important for this reason. The most commonly used method for parasitological studies is scanning electron microscopy (SEM). Sometimes conventional SEM is not acceptable because only a small number or only one sample of a rare parasite is available [1]. The purpose of this work is to show the results of unique observations of basics groups of helminth parasites (roundworms, tapeworms, flukes and spiny headed worms) by environmental scanning electron microscopy (ESEM) with minimal shape and volume deformations. We also show the advantages of studying of these specific types of biological samples in controlled dynamically changing conditions in the specimen chamber of a non-commercial ESEM AQUASEM II.

The specificity of the ESEM AQUASEM II is based on new methods [2, 3] and instrumentation [4, 5]. This microscope is equipped with many types of special detectors (for example by the ionization detector of SEs used in this work), specially designed hydration system and custom-built Peltier cooled specimen holder. The possibility to use the ESEM AQUASEM II for the study of susceptible samples in their native state has been previously shown in the study of live and surviving mites [2], human embryonic stem cells, etc. Representatives from four groups of parasites fixed in $4 \%$ formaldehyde or $70 \%$ ethanol were investigated using ESEM. The samples were cooled down to $2^{\circ} \mathrm{C}$ and observed in a high pressure water vapour environment of 680-600 Pa, probe current 110 pA and beam accelerating voltage $20 \mathrm{kV}$. Samples were placed on a Peltier cooled specimen holder onto a drop of water. Consequently the water was slowly evaporated from the sample, see Fig. 1.

ESEM seems to be very useful when specimens cannot be processed for conventional SEM, because the sample is valuable and cannot be fixed, dehydrated and coated before observation. ESEM allows the examination of specimens in a fully hydrated state and without any previous preparations. This method can be used effectively in taxonomical studies of the parasites, see Fig 2. After examination by ESEM the sample is well preserved and can be used for molecular study or can be processed in another way. Fig. 1 shows time lapse images studied under dynamically changed conditions. Very slowly and well controlled humidity decreasing allows the visualisation of the surface topography of the sample free of dehydration. Samples are well preserved and show features important for the determination of species. For example Figs. 2 show well retained morphological characters such as the oral sucker and genital atrium on a fluke (Trematoda) (Fig. 2A), rostellum with hooks of tapeworm (Cestoda) (Fig 2B) and three single papilla and amphid in a subadult mermithid roundworm (Nematoda) (Fig 2C). Until now only a few authors have used ESEM to study parasites, e.g. [1, 6, 7, 8, 9]. In future research this technique would also be used on living samples of parasites. Acknowledgments go to the grants [9]. 


\section{References:}

[1] Š Mašová et al, CISCEM 2014 Book of Abstracts (2014), p. 106.

[2] E Tihlař́ḱková et al, Microsc Microanal 19 (2013), p. 914.

[3] V Neděla et al, Microsc Res Techniq 78 (2015), p. 13.

[4] J Jirák et al, J Microsc 239 (2010), p. 233.

[5] V Neděla et al, Nucl Instrum Meth 645 (2011), p. 79.

[6] EJ Lopez Torres et al, Vet Parasitol 196 (2013) p. 409.

[7] C Maia-Brigagão et al, Micron 43 (2012), p. 494.

[8] Š Mašová et al, Folia Parasitol 57 (2010), p. 280.

[9] The authors acknowledge funding from the Czech Science Foundation: grants Nos.GA14 22777S and P505/12/G112. The authors are grateful to the staff of the Antarctic expedition 2014 in the Czech Antarctic Station “'J. G. Mendel”' on James Ross Island for providing spiny headed worms.
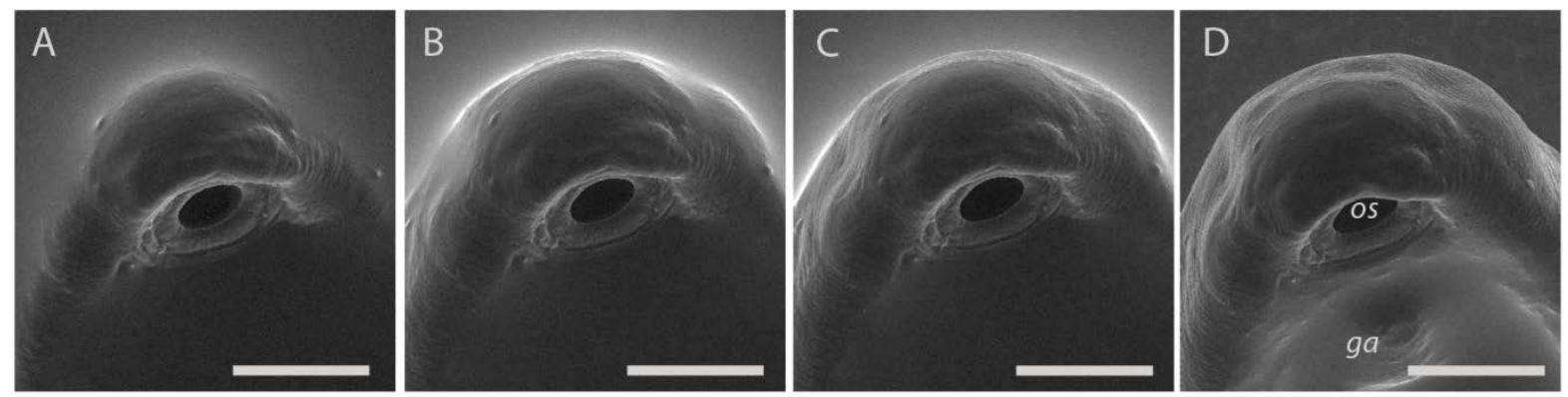

Figure 1. Sequential drying of fish trematode documented by ESEM AQUASEM II. Anterior part of the trematode shows the oral sucker (os) in Figs. A-D and genital atrium ( $g a$ ) in Fig. D. Observation parameters: stage temperature $2^{\circ} \mathrm{C}$, water vapour pressure $690-670 \mathrm{~Pa}$, distance between the sample surface and the second pressure limiting aperture $2.7 \mathrm{~mm}$, accelerating voltage $20 \mathrm{kV}$ and probe current 90 pA. Scale bars $200 \mu \mathrm{m}$.
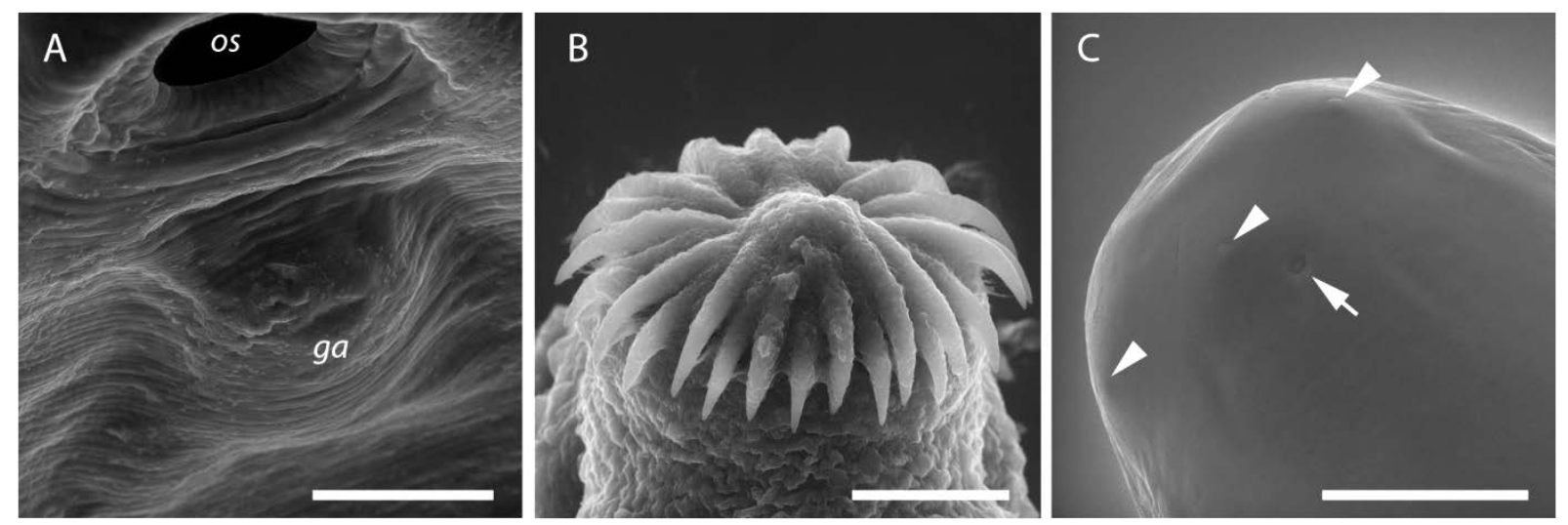

Figure 2. Detailed view of different parasites. A. Detail of fluke (Trematoda) with well visible oral sucker (os) and genital atrium (ga). Scale bar $100 \mu \mathrm{m}$. B. Detailed view of rostellar hooks of a tapeworm (Cestoda). Scale bar $20 \mu \mathrm{m}$. C. Detail of cephalic part of a roundworm (Nematoda). Arrowheads show cephalic papillae and arrows indicate the amphid (chemoreceptor organ). Scale bar $100 \mu \mathrm{m}$. Observation parameters of Figs. A-C: stage temperature $2{ }^{\circ} \mathrm{C}$, water vapour pressure $680 \mathrm{~Pa}$, distance between the sample surface and the second pressure limiting aperture $2.7 \mathrm{~mm}$, accelerating voltage $20 \mathrm{kV}$ and probe current $90 \mathrm{pA}$. 